Check for updates

Cite this: RSC Adv., 2018, 8, 20462

\section{Antidiabetic and hypolipidemic activities of eburicoic acid, a triterpenoid compound from Antrodia camphorata, by regulation of Akt phosphorylation, gluconeogenesis, and PPAR $\alpha$ in streptozotocin-induced diabetic mice}

\begin{abstract}
Cheng-Hsiu Lin, ${ }^{a}$ Yueh-Hsiung Kuo ${ }^{\mathrm{b}}$ and Chun-Ching Shih (D) *c
The study is designed to examine the potential effects and underlying mechanisms of eburicoic acid (TRR), a compound from Antrodia camphorata, in streptozotocin (STZ)-induced diabetic mice. Diabetic mice were randomly divided into six groups and given TRR orally by gavage (at three dosage rates) or fenofibrate (Feno) (250 $\mathrm{mg} \mathrm{kg}^{-1}$ body weight) or metformin (Metf) (300 $\mathrm{mg} \mathrm{kg}^{-1}$ body weight) or vehicle for 2 weeks. STZinduced diabetic mice were found to have increased blood glucose, $\mathrm{HbA1} 1_{C}$, plasma triglyceride (TG) and total cholesterol (TC) levels, but reduced blood insulin, adiponectin, and leptin levels as compared with the CON group. TRR was found to lower blood glucose and $\mathrm{HbA}_{C}$, but increase insulin levels. Plasma TG and TC levels were significantly lowered in TRR, Feno, or Metf-treated STZ-induced diabetic mice as compared with the vehicle-treated STZ group, indicating that TRR, Feno, and Metf ameliorated hyperlipidemia. The islet cells of STZ-induced diabetic mice exhibited a marked reduction from their classic round-shape as compared to the CON mice. The TRR-treated STZ mice revealed restoration of the size of Langerhans islet cells with $\beta$-cell repair as compared with the vehicle-treated STZ mice, implying that TRR ameliorated STZ-induced diabetic states within the pancreas. STZ-induction was found to decrease the expressions of membrane glucose transporter 4 (GLUT4), and phosphorylation of Akt in skeletal muscles, and administration of TRR reversed all the decreases. Moreover, administration of TRR increased blood insulin levels and enhanced hepatic expression levels of phospho-Akt and phospho-FoxO1 but decreased the mRNA levels of glucose-6-phosphatase (G6 Pase) and phosphoenolpyruvate carboxykinase (PEPCK) to suppress hepatic glucose production, thus leading to TRR's antidiabetic activity. Additionally, TRR caused an increase in the expression levels of fatty acid oxidation gene peroxisome proliferator-activated receptor $\alpha$ (PPAR $\alpha$ ), but a decrease in lipogenic fatty acid synthase (FAS) and PPAR $\gamma$ expressions in the liver. TRR treatment suppressed hepatic mRNA levels of sterol regulatory element binding protein (SREBP) $1 \mathrm{c}$ and SREBP2, leading to decreased plasma triglyceride and total cholesterol levels. These findings indicate that TRR may effectively enhance therapeutic potential in the treatment of type 1 diabetes mellitus and/or hyperlipidemia.
\end{abstract}

Received 2nd March 2018 Accepted 24th May 2018

DOI: $10.1039 / \mathrm{c} 8 \mathrm{ra01841c}$ rsc.li/rsc-advances
Diabetes mellitus type 1 (also known as type 1DM) is a metabolic disorder characterized by chronic hyperglycemia, and the pathophysiology is a destruction of the insulin-producing beta cells of the islets of Langerhans in the pancreas, thus leading to insulin deficiency. Type 1DM causes an estimated $5-10 \%$ of all diabetes cases. ${ }^{1}$ Type $1 \mathrm{DM}$ is associated with many complications, and they are considered the causes of morbidity and mortality in patients with diabetes, and it must be clinically managed with insulin injections.

Streptozotocin (STZ) is one of the most universally used diabetogenic agent to induce diabetes in experimental animals. ${ }^{2}$ Streptozotocin is widely used in inducing experimental animal models of type $1 \mathrm{DM}^{3,4}$ Streptozotocin is a nitric oxide donor, and nitric oxide could bring about the destruction of pancreatic islet 
cells. Streptozotocin was demonstrated to generate reactive oxygen species (ROS), which contributed to DNA fragmentation and evoked other deleterious changes within the pancreatic tissue.,

Antrodia cinnamomea (Antrodia camphorata) is a precious edible as a traditional Chinese medicine in Taiwan. Since its growth only on the inner heartwood wall of the endemic evergreen Cinnamomum kanehirae, it is rare and expensive. The identified compositions of $A$. cinnamomea were included as the followings: the fruiting body comprised terpenoids (including antcin A, antcin B, and antcin C), zhankuic acid A, B, C, D and E, 15 $\alpha$-acetyldehydroxysulphurenic acid, dehydroxyeburicoic acid, dehydroxysulphurenic acid, antcin $\mathrm{E}$ and $\mathrm{F}$, methyl antcinate $\mathrm{G}$ and $\mathrm{H}$, benzenoids, succinic and maleic acid. The submerged whole broth contained 10-hydroxy- $\gamma$-dodecalactone, 11-hydroxy- $\gamma$-dodecalactone, 2-(2-hydroxyethyl)phenol, 12-hydroxydodecanoic acid methyl ester, together with eight known compounds, such as ergostatrien-3 $\beta$-ol and ergosterol peroxide. The mycelium consisted of antroquinonol, 4-acetylantroquinonol $\mathrm{B}$, succinic and maleic derivatives, antrodin A, C, E, D, and antrodan.

Antrodia camphorata exhibits numerous physiological functions. Its mycelia display anticancer activity, ${ }^{7}$ liver protection, ${ }^{\mathbf{8}}$ and immunomodulation, ${ }^{9}$ and its submerged culture displays antioxidant and scavenging free radicals activity. ${ }^{10}$ Our recent studies have found that ergostatrien-3 $\beta$-ol, ${ }^{11}$ dehydroeburicoic acid, ${ }^{12,13}$ and antcin $\mathrm{K}^{\mathbf{1 1}}$ from $A$. camphorata showing excellent antidiabetic and antihyperlipidemic activities in different diabetic animal models. These compounds belong to one of triterpenoids from the fruiting body, mycelium, and submerged whole broth of $A$. camphorata. Free radical scavenging molecules, such as terpenoids, tannins, lignins, flavonoids, alkaloids, phenols, and other metabolites are reported to display rich in antioxidant activity. ${ }^{\mathbf{1 4}}$ Streptozotocin by itself was demonstrated to generate ROS. Eburicoic acid (TRR) is an active ergostane type triterpenoid from cultivated Antrodia cinnamomea. Nevertheless, the antidiabetic and antihyperlipidemic effect of TRR is not well defined in STZ-induced diabetic mice.

Therefore, the present study was designed to evaluate whether TRR may display potential metabolic efficacy, including glucose and lipid lowering effects in STZ-induced diabetic mice. Moreover, the protective effects of TRR on the histological examinations of the pancreatic islets of Langerhans and $\mathrm{HbA} 1_{\mathrm{C}}$ levels were evaluated. In this study, Feno, and Metf were used as positive controls, although Metf not for the clinic type $1 \mathrm{DM}$ treatment but for additive effects. And this study was also examined how TRR regulated various gene expressions in skeletal muscles and liver tissues, including hepatic glucose metabolism, hepatic glucose production genes including glucose-6-phosphatase (G6 Pase), which are rate-limiting gluconeogenic enzymes, ${ }^{15}$ and lipid metabolism such as specific changes in hepatic lipogenic fatty acid synthase (FAS) and fatty acid oxidation genes PPAR $\alpha$ are also determined.

\section{Materials and methods}

\subsection{Chemicals}

Antibodies to GLUT4 (no. sc-79838) were obtained from Santa Cruz Biotech (Santa Cruz, CA, USA). Phospho-AMPK (Thr ${ }^{172}$ ), PPAR $\alpha$ (no. ab8934), and PPAR $\gamma$ (no. ab45036) antibodies were purchased from Abcam Inc. (Cambridge, MA, USA). FAS (no. 3180), phosphoAkt $\left(\mathrm{Ser}^{473}\right)$ (no. 4060), total AMPK $\left(\mathrm{Thr}^{172}\right)$, phospho-FoxO1 $\left(\mathrm{Ser}^{256}\right)$ (no. 11115), total-FoxO1 ( $\mathrm{Ser}^{256}$ ) (no. 2880), and $\beta$-actin (no. 4970) antibodies were obtained from Cell Signaling Technology (Danvers, MA, USA). Secondary anti-rabbit antibodies were purchased from Jackson ImmunoRes. Lab., Inc. (West Grove, PA, USA).

\subsection{Isolation and determination of the active compound}

The mycelium of Antrodia camphorata (=Antrodia cinnamomea) was obtained from the Grape King Biotech Co. Ltd. (Chiayi City, Taiwan). Freeze-dried powders of the mycelia of Antrodia camphorata $(3.0 \mathrm{~kg})$ were extracted three times with methanol $(12 \mathrm{~L})$ at room temperature $(4$ days $\times 3)$. The methanol extract was evaporated in vacuo to yield a brown residue, which was suspended in $\mathrm{H}_{2} \mathrm{O}(1 \mathrm{~L})$ and partitioned with ethyl acetate $(1 \mathrm{~L} \times 3)$. The EtOAc fraction (200 g) was chromatographed on silica gel using mixtures of hexane and EtOAc of increasing polarity as eluents and further purified with HPLC (Shimadzu CL 20-A, Kyoto, Japan) on a Hibar pre-packed column RT 250-10 with

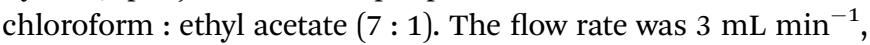
and the injection volumes of samples were $100 \mu \mathrm{L}$. This part of the procedure was performed in accordance with prior reports. ${ }^{\mathbf{1 6}}$ Eburicoic acid (TRR) was isolated by HPLC on a Hibar pre-packed column RT 250-10 with chloroform : ethyl acetate $(7: 1)$ and a refractive index (RI) (Knauer RI detector 2400), and the flow rate

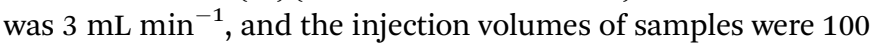
$\mu$ L. ${ }^{12,16-18}$ Eburicoic acid (TRR) and dehydroeburicoic acid (TR2) were isolated by HPLC on a Hibar pre-packed column RT 250-10 and using a refractive index (RI) detector (Knauer RI detector $2400)$ with chloroform : ethyl acetate $(7: 1)$. The flow rate was 3 $\mathrm{mL} \min ^{-1}$, and the injection volumes of samples were $100 \mu \mathrm{L}$. The yields of TRR and TR2 obtained were about $0.1 \%$ and $0.2 \%$ (w/w). The purity of TRR and TR2 were higher than 99\%. TRR: ${ }^{1} \mathrm{H}$ NMR (300 MHz, pyridine- $\left.\mathrm{d}_{5}\right) ; \delta 3.41(1 \mathrm{H}$, br t, $J=7.6 \mathrm{~Hz}, \mathrm{H}-3)$, 1.00 (3H, s, H-18), 1.06 (3H, s, H-19), $2.63(1 \mathrm{H}, \mathrm{td}, J=2.4$, $10.6 \mathrm{~Hz}, \mathrm{H}-20), 2.27$ (1H, m, H-25), 1.01 (6H, d, $J=7.6 \mathrm{~Hz}, \mathrm{H}-26$ and $\mathrm{H}-27), 4.87$ (1H, br s, H-28a), 4.91 (1H, br s, H-28b), 1.05 (3H, s, H-29), 1.22 (3H, s, H-30), 1.00 (3H, s, H-31).

\subsection{Cell culture}

Myoblast C2C12 cells (ATCC, CRL-1772) were kept in DMEM supplemented with $10 \%$ heat inactivated FBS, $100 \mathrm{U} \mathrm{mL}^{-1}$ penicillin, and $100 \mu \mathrm{g} \mathrm{mL} \mathrm{m}^{-1}$ streptomycin in a humidified atmosphere with $5 \% \mathrm{CO}_{2}$ at $37{ }^{\circ} \mathrm{C}$. Cells for differentiation into myotubes were reseeded in $9 \mathrm{~cm}$ plates at a density of $1 \times 10^{5}$ cells. After $48 \mathrm{~h}$ (over $80 \%$ confluence), the medium was switched to DMEM with $1 \%$ (v/ v) FBS and was replaced after 2, 4, and 6 days of culture. The treatments of cells with TRR or insulin were initiated on day 6 when myotube differentiation was complete, and this part method has been described in our previous publication. ${ }^{19}$

\subsection{Analysis of phospho-Akt (Ser 473)/total Akt proteins in C2C12 myotubes}

Supernatant protein concentration was determined via BCA assay (Pierce). Equal amounts of protein were then diluted $4 \times$ 
in SDS sample buffer (62.5 mM Tris-HCl, 20\% glycerol, $2 \%$ SDS, 75 M DTT, and $0.05 \%$ bromophenol blue), subjected to SDS PAGE and were detected by western blotting with antibodies specific for total-Akt (t-Akt) and phospho-Akt (Ser ${ }^{473}$ ) (p-Akt). The density blotting was analyzed using Alpha Easy FC software (Alpha Innotech Corp., Randburg, South Africa).

\subsection{Animal study}

All animal studies were approved by the guidelines of the Affidavit of Approval of Animal Care and Use Protocol Central Taiwan University of Science and Technology (no: 105-CTUST-03 part1) and were conducted in accordance to the Local Animal Ethics Committee (Animal Ethics Committee, permit \#P105-I07). The 4 week old male C57BL/6J mice $(n=56)$ obtained from the National Laboratory Animal Breeding Center. Streptozotocin (Sigma Chemical, St Louis, MO, USA) was dissolved in $0.05 \mathrm{M}$ cold sodium citrate buffer, $\mathrm{pH}$ 4.5. Diabetes was induced by five daily $55 \mathrm{mg}$ $\mathrm{kg}^{-1}$ intraperitoneal injections of streptozotocin solution over five days, and then for a two-week waiting period. A group of control $(\mathrm{CON})$ mice $(n=8)$ were gavaged identical volumes of vehicle. The STZ mice that were found to develop hyperglycemia, defined as fasting blood glucose above $250 \mathrm{mg} \mathrm{dL}^{-1}$, were considered to have diabetes for this study. ${ }^{19,20}$ The STZ-induced diabetic mice $(n=48)$ were then randomly divided into six groups treated as follows: (1) control vehicle (STZ control group) (with similar volumes); (2) three groups were administered of TRR at either 10,20 , or $40 \mathrm{mg} \mathrm{kg} \mathrm{kg}^{-1}$ (groups TRR1, TRR2, or TRR3, respectively); (3) two comparator groups were treated with fenofibrate (Feno) (250 $\mathrm{mg} \mathrm{kg}^{-1}$ ), or metformin (Metf) (300 mg kg-1). The vehicle, TRR or Feno or Metf was treated by oral gavage once per day for 14 days. For assessment of blood parameters, during the experiment, all mice were fasted overnight, and blood samples (about 150-200 $\mu \mathrm{L}$ ) were collected from the retro-orbital sinus. At the end, mice were anesthetized with carbon dioxide. The liver and adipose tissue, skeletal muscle, and white adipose tissues (WATs) (including epididymal, mesenteric and retroperitoneal WAT) were harvested to detect the targeted gene expressions and determine the relative organ weight and instantly frozen at $-80{ }^{\circ} \mathrm{C}$. In addition to blood glucose, heparin (30 units per $\mathrm{mL}$ ) (Sigma) was firstly added into the collecting blood tubes, and then tubes were dried. These heparinprocessed tubes were instantly used to collect blood samples. After 15 min centrifugation of whole blood at $1600 \mathrm{~g}$ at $4{ }^{\circ} \mathrm{C}$, plasma samples were collected (this separation was done within 30 minutes) and the supernatant were subjected to total cholesterol (TC) and triglyceride (TG) measuring (individually 20-30 $\mu \mathrm{L}$ ). Aliquots of plasma samples $(>25 \mu \mathrm{L})$ were obtained for assessment of levels of insulin, leptin, and adiponectin. Body weight was daily measured (A.M. 10:00) at the same time duration the experiment. Mice were monitored carefully for clinical health signs attributable to body weight changing, skin disease, food consumption, and the appearance of the animals. Mice were monitored for food intake per day according to weighing the amount of put pellet food, and the amount of remaining food after $24 \mathrm{~h}$, and the difference is represented the food intake per day, and this animal study method has been described in our previous publication with minor modification. ${ }^{19}$

\subsection{Analysis of blood glucose, triglyceride, total cholesterol, adipocytokine, and $\mathrm{HbA1}_{\mathrm{C}}$ levels}

Blood samples were collected from the retro-orbital sinuses of 10-12 $\mathrm{h}$ fasted mice, and the samples $(>20 \mu \mathrm{L})$ immediately were placed on tinfoil paper and quickly on machines. Blood glucose levels were measured from the retro-orbital sinuses of 10-12 h fasted mice by the glucose oxidase method (Model 1500; Sidekick Glucose Analyzer; YSI Incorporated, Yellow Springs, USA). Levels of TG and TC were analyzed using commercial assay kits in accordance with manufacturer directions (Triglycerides-E test and Cholesterol-E test, Wako Pure Chemical, Osaka, Japan). Aliquots of plasma samples $(>25 \mu \mathrm{L})$ were used for assessment of levels of insulin, leptin, and adiponectin by enzyme-linked immunosorbent assay (ELISA) kits (mouse insulin ELISA kit, Mercodia, Uppsala, Sweden; mouse leptin ELISA kit, Morinaga, Yokohama, Japan), as demonstrated in previous procedures. ${ }^{11,12,20,21}$ Percent $\mathrm{HbA} 1_{\mathrm{C}}$ was measured with a Hemoglobin $\mathrm{A}_{1 \mathrm{C}}$ kit (BioSystems S.A., Barcelona, Spain).

\subsection{Histological examinations}

Small pieces of liver tissues and pancreas samples were fixed with formalin (200 $\mathrm{g} \mathrm{kg}^{-1}$ ) neutral buffered solution and embedded in paraffin. Sections $(8 \mu \mathrm{m})$ were cut and stained with hematoxylin and eosin. Liver tissues, pancreas, and epididymal WAT samples were further studied by a microscope (Leica, DM2500) using a Leica Digital camera (DFC-425-C) at magnification of 10 (ocular) $\times 20$ (object lens) for liver tissues, pancreas, and adipose tissue samples.

\subsection{Relative quantification of mRNA and western blotting}

Relative mRNA quantification (primers are described in Table 1) and immunoblots for analysis of expression levels of skeletal muscular membrane GLUT4 and hepatic phospho-AMPK $\left(\mathrm{Thr}^{172}\right)$ (p-AMPK) were performed as described in previously reported studies. ${ }^{\mathbf{1 1 , 1 2 , 2 1}}$ Evidence have been shown that phosphorylation of Threonine 172 (Thr172) of the $\alpha$ subunit is essential for AMPK activity. ${ }^{22}$ Protein extracts from the liver tissue samples were run on SDS-PAGE for detection of expression levels of PPAR $\alpha$ and FAS, and adipose tissue samples for measurement of expressions of PPAR $\gamma$ and FAS. The skeletal muscle samples from mice were subjected to assessment of expression levels of GLUT4, and total membrane fraction was collected and measured as demonstrated in our previous procedure. $^{23,24}$ Skeletal muscle was powdered under liquid nitrogen and homogenized in buffer ( $\mathrm{pH}$ 7.4) containing $250 \mathrm{mmol} \mathrm{L}^{-1}$ sucrose, $50 \mathrm{mmol} \mathrm{L}{ }^{-1}$ Tris, and $0.2 \mathrm{mmol} \mathrm{L}^{-1}$ edetic acid for $20 \mathrm{~s}$. The homogenate was centrifuged at $9000 \times$ $g$ for $10 \mathrm{~min}\left(4^{\circ} \mathrm{C}\right)$ and the supernatant was reserved. The pellets were cleaned with buffer and centrifuged for three times. All three supernatants were mixed and centrifuged at $190000 \times g$ for $60 \mathrm{~min}\left(4^{\circ} \mathrm{C}\right)$. The resulting pellet was resuspended in a small amount of buffer (about $0.5 \mathrm{~mL}$ ) as a total membrane fraction. ${ }^{\mathbf{2 3 2} 2}$ The expression levels of membrane GLUT4, pAMPK, and total-AMPK ( $\mathrm{t}$-AMPK) were determined by western blotting as demonstrated in previous procedures. ${ }^{11,12,23}$ 
Table 1 Primers used in the present study

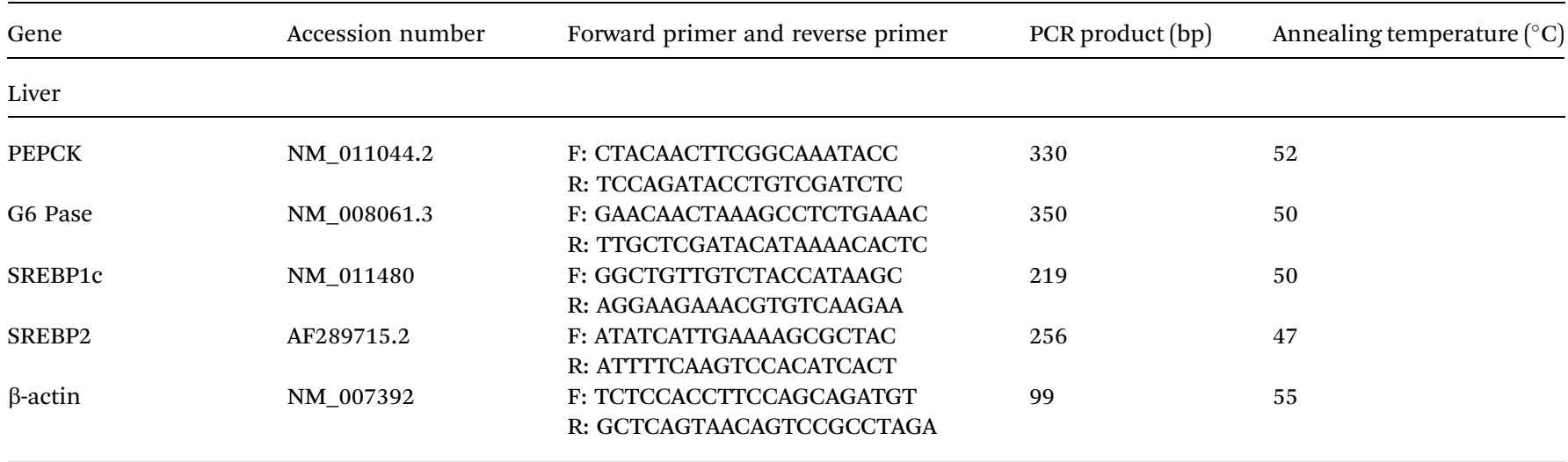

\subsection{Statistical analysis}

All results were presented as the mean and standard error. Whenever possible, data were subjected to analysis of variance, and then by Dunnett's multiple range tests, using SPSS software (SPSS Inc., Chicago, IL, USA). $p<0.05$ is regarded as statistically significant.

\section{Results}

\subsection{Phospho-Akt (Ser 473)/total Akt proteins in C2C12 myotubes}

The phospho-Akt (Ser 473)/total Akt expression levels of TRR treatment (at 10, 30, and $60 \mathrm{~min}$ ) were shown to activate Akt in a time-dependent manner $(p<0.05, p<0.05, p<0.01$, respectively). The effect of Akt activation at $60 \mathrm{~min}$ after TRR treatment was comparable to that of insulin (Fig. 1(A) and (B)).

\subsection{Body weight and relative tissue weight}

At the beginning, the arrived body weight of all mice was 17.13 \pm 0.19 g. After 7 day acclimatization, at the end of STZinduction and the beginning of vehicle, TRR, Feno, or Metf treatment, the body weight of the CON group was $21.45 \pm 0.48 \mathrm{~g}$ and that of STZ mice was $19.16 \pm 0.60 \mathrm{~g}(p<0.05)$. Then, mice received their drug treatment for 2 weeks. At the end of the animal study, the STZ-induced diabetic mice decreased the final body weight as compared to the CON mice $(p<0.05)$. The final body weight of TRR-, Feno-, or Metf-treated STZ groups did not differ from that of the vehicle-treated STZ group (Fig. 2(A)). The relative weights of epididymal and retroperitoneal WAT, and visceral fat of STZ-group were found to significantly decrease as compared to that of the CON group ( $p<0.001, p<0.001, p<$ 0.001 , respectively). There is no significant difference in the relative weights of epididymal, mesenteric, and retroperitoneal WAT, and visceral fat between those of TRR- and Feno-treated STZ mice and the vehicle-treated STZ mice (Fig. 2(B)). Administration of Metf was found to reduce the relative weights of EWAT and visceral fat (Fig. 2(B)), and Feno treatment markedly enhanced the relative liver weights as compared to those of the STZ mice (Fig. 2(C)).

\subsection{Blood metabolic parameters}

STZ-induction was found to increase blood glucose and $\mathrm{HbA1}_{\mathrm{C}}$ as compared with that of the CON group ( $p<0.001, p<0.001$, respectively). Administration of TRR1, TRR2, and TRR3 displayed significant a reduction in both blood glucose $(p<0.001, p$ $<0.001, p<0.001$, respectively) and HbA1 $1_{\mathrm{C}}$ levels $(p<0.001, p<$ $0.001, p<0.001$, respectively) as compared to the STZ group (Fig. 2(D) and (E)). Plasma TG and TC concentrations of the STZinduced diabetic mice were found to increase as compared with the CON group ( $p<0.001, p<0.001$, respectively). Administration of TRR1, TRR2, TRR3, Feno, or Metf suppressed the STZinduced increases in the concentrations of TG and TC (Fig. 2(F) and (G)). The STZ-induced diabetic mice showed a decrease in blood insulin levels as compared with the CON group ( $p<0.001)$, which was increased in TRR1-, TRR2-, or TRR3-treated mice as compared with the STZ mice $(p<0.001, p$ $<0.001, p<0.001$, respectively) (Fig. 2(H)). STZ-induction was found to reduce blood adiponectin and leptin levels as compared with the CON group ( $p<0.001, p<0.001$, respectively), and TRR1, TRR2, TRR3, Feno, or Metf treatment dramatically enhanced adiponectin and leptin levels as compared with the STZ mice (Fig. 2(I) and (J)).

\subsection{Histological examinations}

The STZ-induced diabetic mice displayed a slight hepatic ballooning degeneration of hepatocytes as compared to the CON group. The present results showed that lipid droplet appear increased in STZ vs. control livers, TRR-induced fat accumulation was not obvious (Fig. 3(A)). The pancreatic islets of Langerhans were found in the field of vision with a light pink-purple color. The control normal mice have shown that the islets were round and well-defined in shape, but without cell distortion. The STZ-induced diabetic mice displayed a reduction in the size of Langerhans islet cells and with a distorted pancreatic architecture (as arrow indicated). STZ-induction resulted in a decrease in the size of the pancreas. The average areas of the pancreas were $8032.8 \pm 286.7$ $\mu \mathrm{m}^{2}$ in the STZ group, and $14029.5 \pm 355.7 \mu \mathrm{m}^{2}$ in the CON group, respectively, while administered of TRR1 (12 151.8 \pm 221.7 $\left.\mu \mathrm{m}^{2}\right)$, and TRR2 (13 979.5 $\left.\pm 271.8 \mu \mathrm{m}^{2}\right)$, TRR3 $(22971.4 \pm 370.1$ $\mu \mathrm{m}^{2}$ ) displayed a significant increase the average areas of the 
A

p-Akt

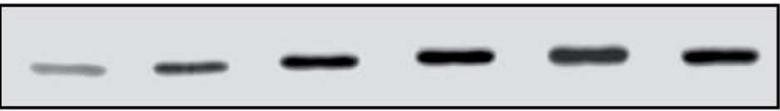

t-Akt
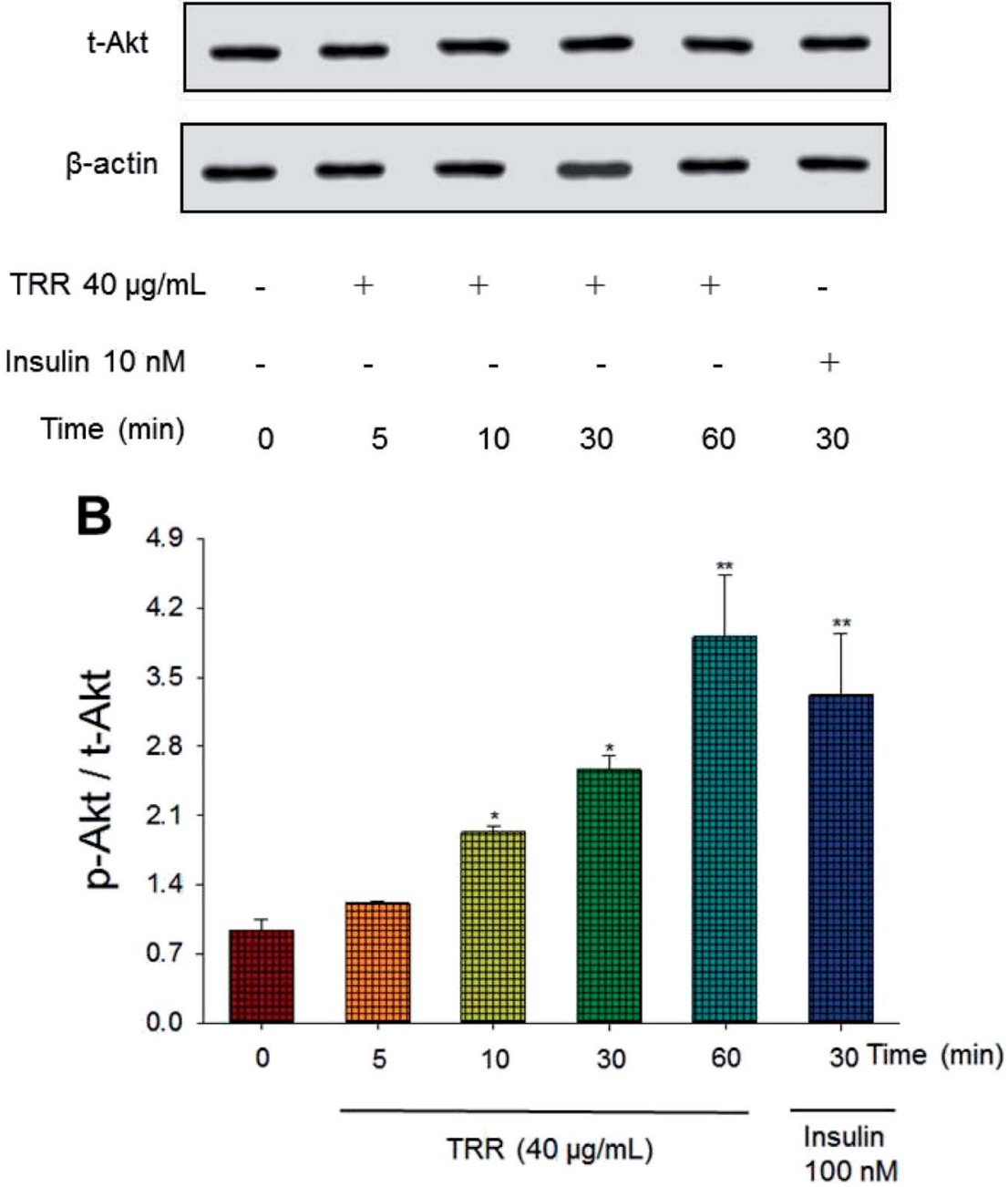

Fig. 1 Eburicoic acid (TRR) activates Akt signaling pathways. The cell lysates were analyzed via western blotting for phospho-Akt ( $p$-Akt) and total-Akt (t-Akt). (A) Representative image; Akt phosphorylation was determined from C2C12 cells, and treated with $40 \mu \mathrm{g} \mathrm{mL}{ }^{-1}$ of TRR for the indicated period of time (5-60 min); (B) the ratios of $p$-Akt to t-Akt forms were analyzed and presented phosphorylation of Akt. * $p<0.05$ and $* * p$ $<0.01$ compared with the 0 min group. All values are means $\pm \mathrm{SE}(n=3)$.

pancreas, and there exists no significant difference in the Fenoand Metf-treated STZ mice $\left(8689.7 \pm 324.7 \mu^{2}, 6619.2 \pm 269.3\right.$ $\mu \mathrm{m}^{2}$, respectively) as compared with the vehicle-treated STZ mice in the size of the pancreas (Fig. 3(B)). Our present results showed that administration of TRR1, TRR2 and TRR3 caused a significant improvement in the size of Langerhans islet cells and with the less distorted pancreatic architecture (Fig. 3(B)). STZ-induced the adipocytes smaller than the CON group in epididymal WAT. Administration of TRR, Feno, Metf caused the adipocytes larger than the vehicle-treated STZ group (Fig. 3(C) and (D)).

\subsection{Hepatic targeted gene mRNA levels}

STZ-induction exerted a significant increase in the mRNA levels of glucose 6-phosphatase (G6 Pase) and sterol regulatory element binding protein 1c (SREBP1c), phosphoenolpyruvate carboxykinase (PEPCK), and SREBP2 as compared to the CON group. Administration of h TRR1, TRR2, TRR3, Feno, and Metf decreased the mRNA levels of G6 Pase, PEPCK, SREBP1c, and SREBP2 as compared to the STZ group (Fig. 4(A) and (B)).

3.6. Expressions of membrane GLUT4, phospho-AMPK $\left(\right.$ Thr $\left.^{172}\right) /$ total-AMPK, and phospho-Akt $\left(\right.$ Ser $\left.^{473}\right) /$ total-Akt $\left(\operatorname{Ser}^{473}\right)$ in skeletal muscles

As shown in Fig. 5, the membrane expressions of GLUT4 were lower in the STZ group than in the CON group in skeletal muscles $(p<0.001)$. Administration of TRR1, TRR2, TRR3, Feno, and Metf increased the membrane expressions of GLUT4 as compared to the STZ group ( $p<0.001, p<0.001, p<0.001, p<$ $0.001, p<0.001, p<0.001$, respectively). The expression levels of $\mathrm{p}$-AMPK/t-AMPK and p-Akt/t-Akt were lowered in the STZ group 

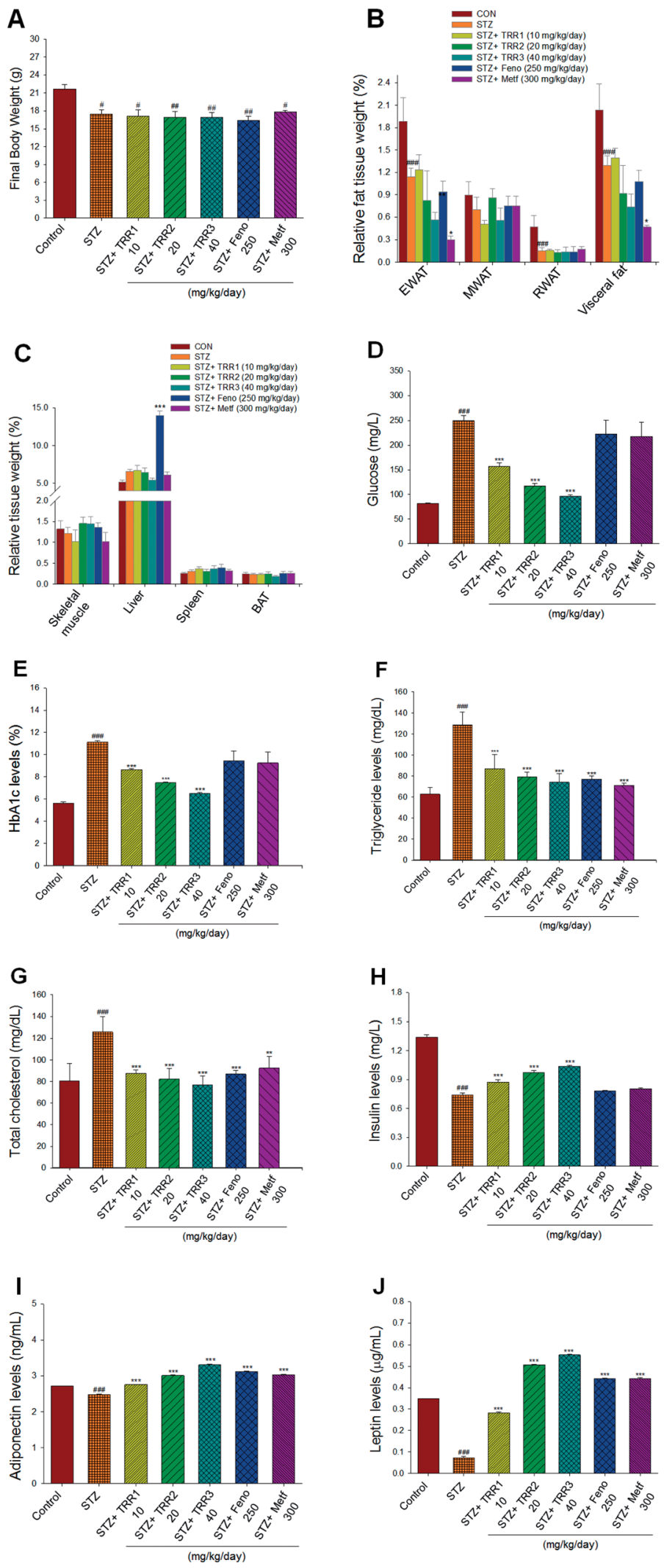

Fig. 2 Effects of eburicoic acid (TRR) on (A) final body weight, (B) relative fat tissue weight, (C) relative tissue weight, (D) blood glucose, (E) HbA1C, $(\mathrm{F})$ triglyceride, (G) total cholesterol, $(\mathrm{H})$ insulin, (I) adiponectin, and (J) leptin levels in streptozotocin-induced diabetic mice. ${ }^{*} p<0.05,{ }^{\# \#} p<0.01$,

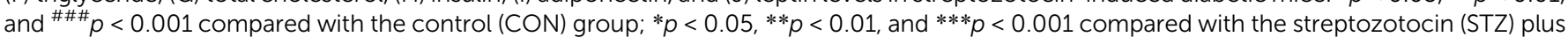

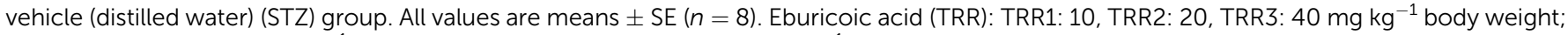
Feno: fenofibrate (250 $\mathrm{mg} \mathrm{kg}^{-1}$ body weight); Metf: metformin (300 $\mathrm{mg} \mathrm{kg}^{-1}$ body weight). RWAT, retroperitoneal white adipose tissue; MWAT, mesenteric white adipose tissue; BAT, brown adipose tissue. 
CON

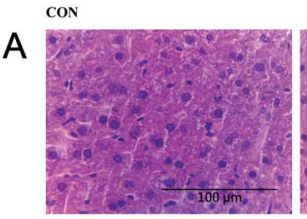

STZ+TRR1

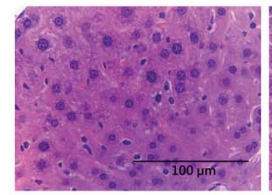

STZ+TRR3

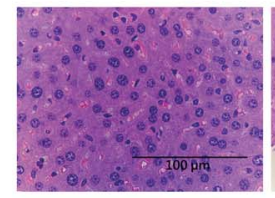

STZ+Metf

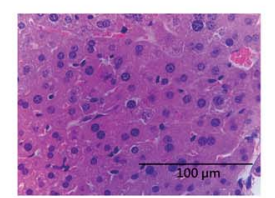

STZ

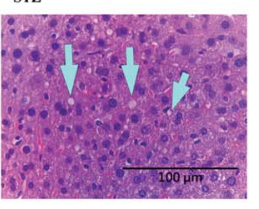

STZ+TRR2

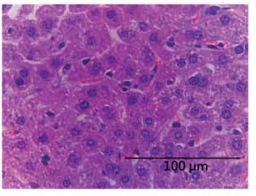

STZ+Feno

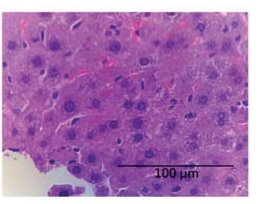

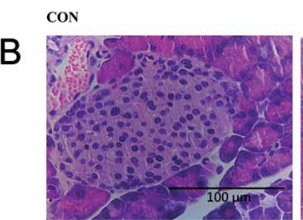

STZ+TRR1

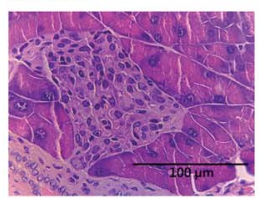

STZ+TRR3

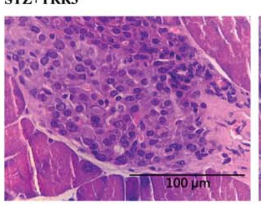

STZ+Metf

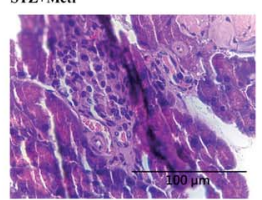

STZ

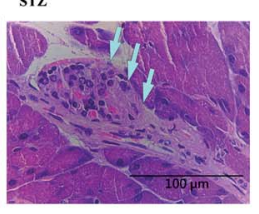

STZ+TRR2

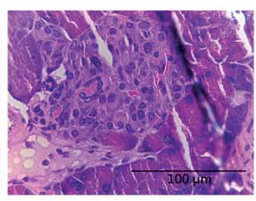

STZ+Feno

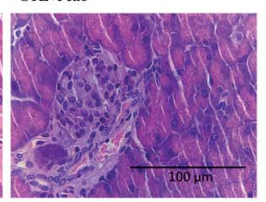

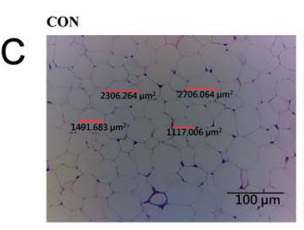

STZ+TRRI

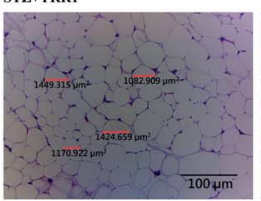

STZ+TRR3

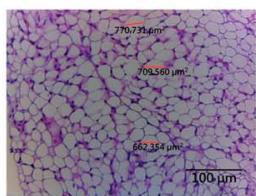

STZ+Metf

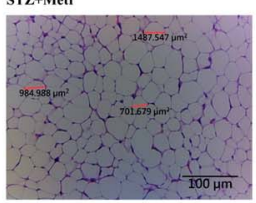

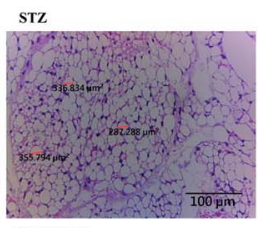

STZ+TRR2

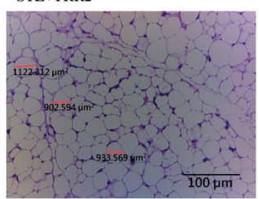

STZ+Feno

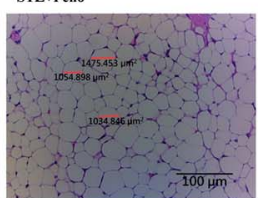

D

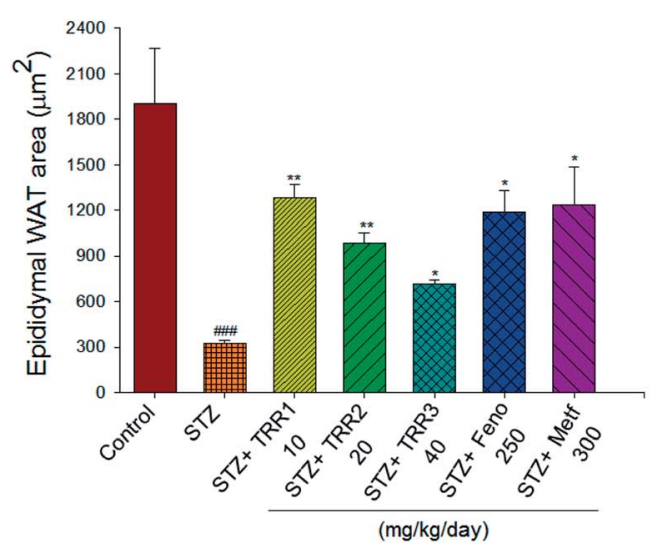

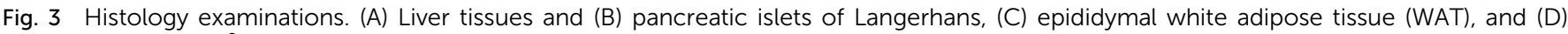

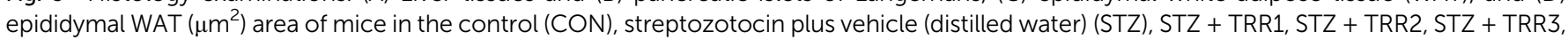

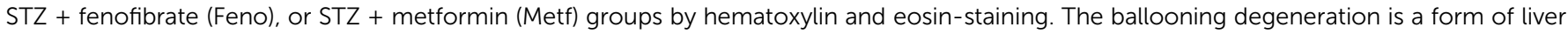

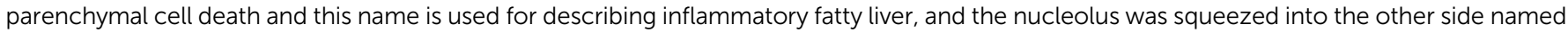

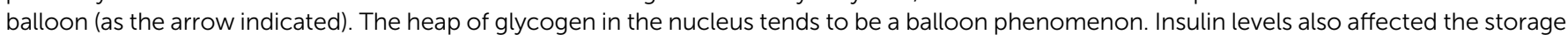

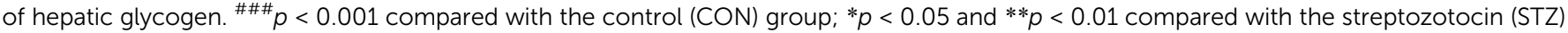

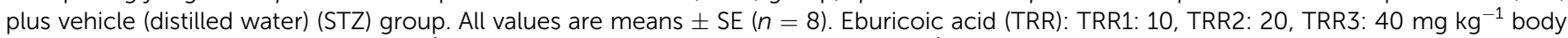
weight; Feno: fenofibrate ( $250 \mathrm{mg} \mathrm{kg}^{-1}$ body weight); Metf: metformin (300 $\mathrm{mg} \mathrm{kg}^{-1}$ body weight).

than in the CON group in the skeletal muscle $(p<0.001, p<$ 0.001 , respectively), and administration of TRR1, TRR2, TRR3, Feno, and Metf enhanced expression levels of p-AMPK/t-AMPK and p-Akt/t-Akt as compared to the STZ group (Fig. 5(A) and (B)).

\subsection{Expressions of phospho-Akt, phospho-forkhead transcription factor Foxo1 (phospho-FoxO1), phospho-AMPK, PPAR $\alpha$, FAS, and PPAR $\gamma$ in liver tissues}

As shown in Fig. 6, the expressions of p-Akt/t-Akt were lower in the STZ group than in the CON group in the liver $(p<0.001)$. Following treatment, the hepatic expressions of $\mathrm{p}$-Akt/t-Akt were enhanced in the TRR1-, TRR2-, TRR3-, Feno-, and Metf-treated groups as compared to the STZ group $(p<0.001, p<0.001, p<$ $0.001, p<0.001, p<0.001$, respectively) (Fig. 6(A)). The hepatic expressions of phospho-FoxO1/total-FoxO1 (p-FoxO1/t-FoxO1) were lowered in the STZ group than in the CON group $(p<$ 0.001); and expression levels of $\mathrm{p}$-FoxO1/t-FoxO1 were increased in the TRR1-, TRR2-, TRR3-, Feno-, and Metf-treated groups as compared to the STZ group (Fig. 6(A) and (B)). The hepatic expression levels of $\mathrm{p}$-AMPK/t-AMPK and PPAR $\alpha$ were decreased in the STZ group as compared to the CON group, and the TRR1-, TRR2-, TRR3-, Feno-, and Metf-treated mice enhanced the 

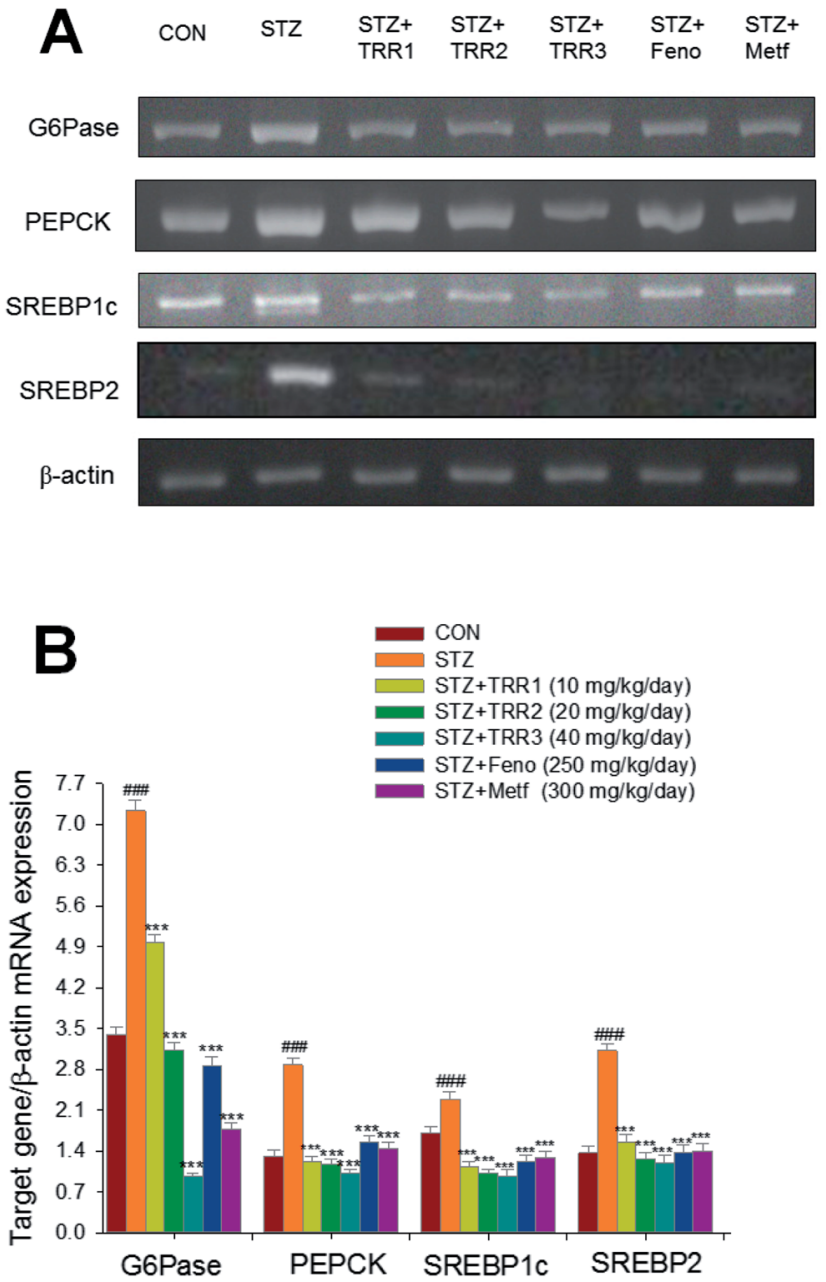

Fig. 4 Semiquantitative RT-PCR analysis on targeted gene mRNA levels in liver tissue of the mice by oral gavage eburicoic acid (TRR) (TRR1, TRR2, and TRR3, 10, 20 and $40 \mathrm{mg} \mathrm{kg}^{-1}$ body weight), fenofibrate (Feno; $250 \mathrm{mg} \mathrm{kg}^{-1}$ body weight), or metformin (Metf; $300 \mathrm{mg}$ $\mathrm{kg}^{-1}$ body weight). (A) Representative image; (B) quantification of the ratio of target gene to GAPDH mRNA expression. Total RNA $(1 \mu \mathrm{g})$ isolated from tissue was reverse transcripted by MMLV-RT; $10 \mu \mathrm{L}$ of RT products were used as templates for PCR. The expression levels of G6 Pase, PEPCK, SREBP1C, and SREBP2 mRNA were measured and quantified by image analysis. Values were normalized to $\beta$-actin mRNA

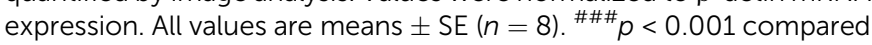
with the control (CON) group; $* * * p<0.001$ compared with the streptozotocin plus vehicle (distilled water) (STZ) group.

hepatic expression levels of p-AMPK/t-AMPK and PPAR $\alpha$ as compared to the STZ group (Fig. 6(C) and (D)). The STZ group was found to display higher expression levels of FAS and PPAR $\gamma$ than did the CON group; and administration of TRR1, TRR2, TRR3, Feno, and Metf expressed lower levels of FAS and PPAR $\gamma$ than did the STZ group in the livers (Fig. 6(C) and (D)).

\section{Discussion}

In this study, we sought to determine whether TRR, a triterpenoid compound of A. camphorata could lower blood glucose levels and prevent hyperlipidemic parameters and examine the possible underlying mechanisms of Akt activation in STZ-
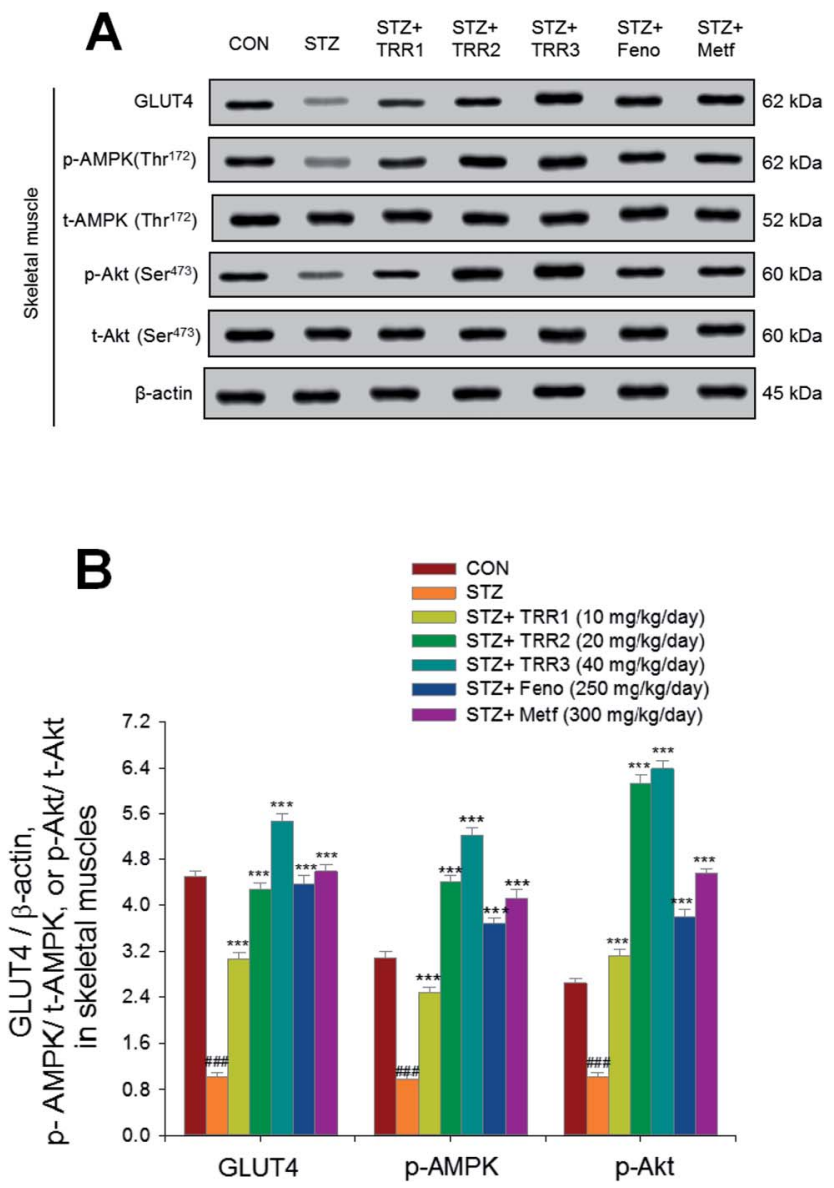

Fig. 5 The expression levels of (A) membrane GLUT4, p-AMPK $\left(\right.$ Thr $\left.^{172}\right) / \mathrm{t}-\mathrm{AMPK}$ and $\mathrm{p}-\mathrm{Akt}\left(\mathrm{Ser}^{473}\right) / \mathrm{t}-\mathrm{Akt}\left(\mathrm{Ser}^{473}\right)$ in the skeletal muscles of STZ-induced diabetic mice by oral gavage eburicoic acid (TRR). (A) Representative image; (B) quantification of the $\mathrm{p}-\mathrm{AMPK}$ to $\mathrm{t}-\mathrm{AMPK}$ and p-Akt $\left(\mathrm{Ser}^{473}\right) / \mathrm{t}-\mathrm{Akt}\left(\mathrm{Ser}^{473}\right)$. Protein was separated by $12 \%$ SDS-PAGE detected by western blot. ${ }^{\# \#} p<0.001$ compared with the control (CON) group; $* * * p<0.001$ compared with the streptozotocin plus vehicle (distilled water) (STZ) group. All values are means \pm SE $(n=8)$. TRR1, TRR2, and TRR3, eburicoic acid (TRR) (TRR1, TRR2, and TRR3, 10, 20, and $40 \mathrm{mg} \mathrm{kg}^{-1}$ body weight, respectively); fenofibrate (Feno, $250 \mathrm{mg} \mathrm{kg}{ }^{-1}$ body weight); metformin (Metf; $300 \mathrm{mg} \mathrm{kg}^{-1}$ body weight).

induced diabetic mice, as a model of type 1 DM. Firstly, in vitro experiment, we found that TRR caused an enhancement of phosphorylation of Akt in C2C12 myotubes in a dose-dependent manner and expression levels of p-Akt reached the maximum at 30 to 60 min after TRR treatment, suggesting that stimulation of activated Akt pathway, similar to insulin (Fig. 1). In the animal study, we have also examined whether TRR could lower the levels of blood glucose and triglyceride in order to maintain blood normal euglycemia and lipidemia. It is shown here that a multiple low dose (MLD)-STZ-injections (55 $\mathrm{mg} \mathrm{kg}^{-1}$ bodyweight for 5 consecutive days) caused hyperglycemia, which is consistent with a previous observation. ${ }^{25}$ Importantly, TRR treatment exhibited a significant decrease in blood glucose and $\mathrm{HbA}_{\mathrm{C}}$ levels and significantly improved the STZ-induced hyperglycemia, but a significant increase in plasma insulin levels in STZ-induced diabetic mice; moreover, TRR exhibited 

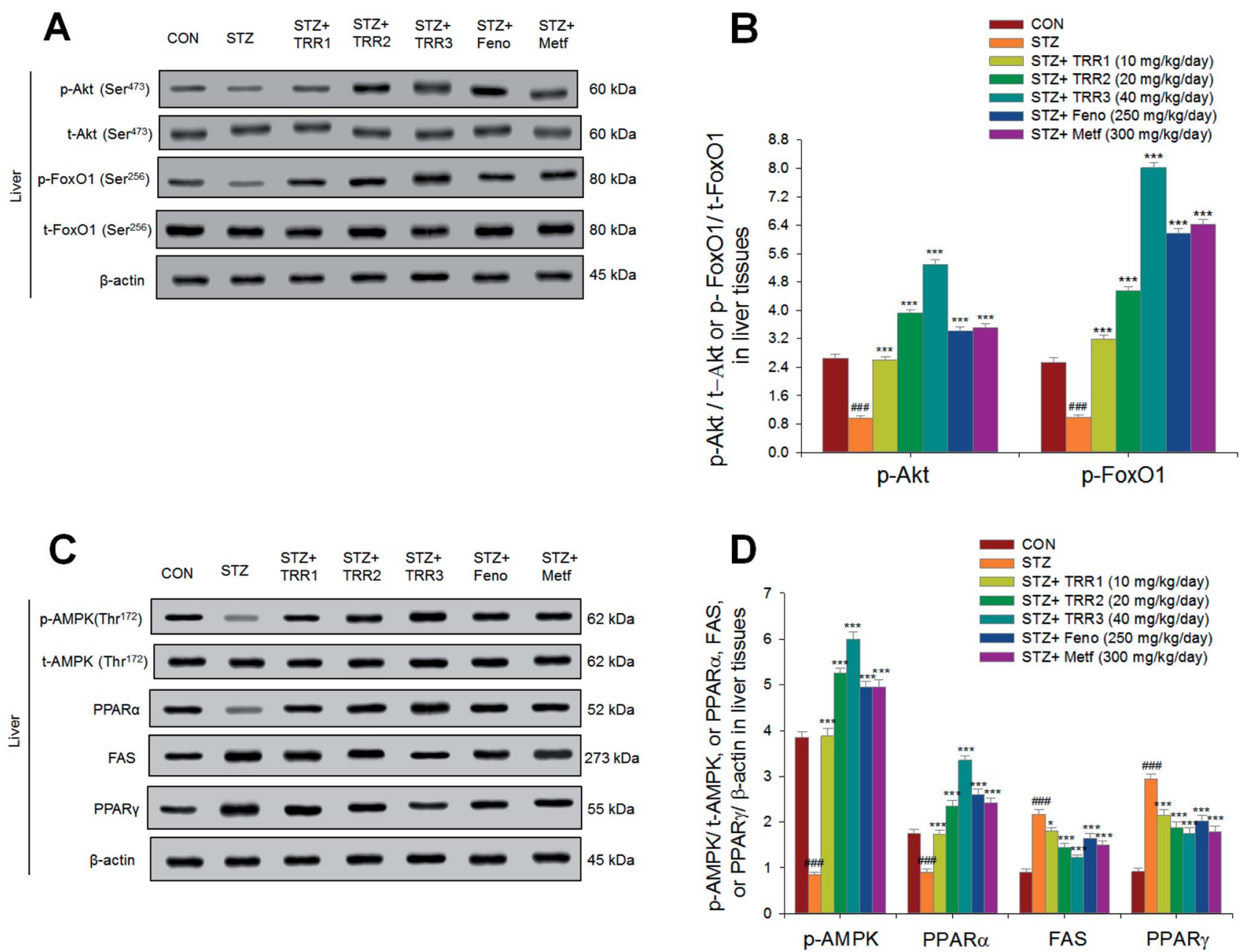

Fig. 6 The expression levels of (A) p-Akt $\left(\mathrm{Ser}^{473}\right) / \mathrm{t}-\mathrm{Akt}\left(\mathrm{Ser}^{473}\right)$ and p-FoxO1 $\left(\mathrm{Ser}^{256}\right) / \mathrm{t}-\mathrm{FoxO1}\left(\mathrm{Ser}^{256}\right)$, (B) p-AMPK (Thr $\left.{ }^{172}\right) / \mathrm{t}-\mathrm{AMPK}, \mathrm{PPAR} \alpha$, FAS, and PPAR $\gamma$ in the liver tissues of STZ-induced diabetic mice by oral gavage eburicoic acid (TRR). (A and B) Representative image; (C and D) quantification of the $\mathrm{p}$-AMPK to t-AMPK, PPAR $\alpha$, FAS, and PPAR $\gamma$. Protein was separated by $12 \%$ SDS-PAGE detected by western blot. All values are means \pm SE $(n=8)$. ${ }^{\# \# \# ~} p<0.001$ compared with the control (CON) group; $* p<0.05, * * * p<0.001$ compared with the streptozotocin plus

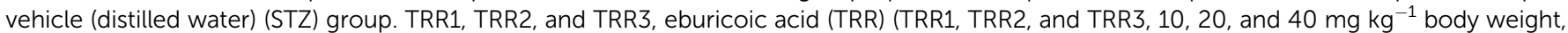
respectively); fenofibrate (Feno, $250 \mathrm{mg} \mathrm{kg}^{-1}$ body weight); metformin (Metf; $300 \mathrm{mg} \mathrm{kg}^{-1}$ body weight).

the increased size of Langerhans islet cells and less distorted architecture within the pancreas (Fig. 3(B)), suggesting that antioxidant effect within $\beta$-cells against STZ-induced oxidant stress of these beneficial blood metabolic effects, thus leading to TRR's anti-hyperglycemic effects.

Chronic hyperglycemia in diabetes mellitus may lead to excess free radical production and reactive oxygen species (ROS), thus resulting in the development of a variety of diabetic complications known with high oxidative stress levels. ${ }^{26,27}$ In this study, TRR exhibits the protective activity against oxidant damage not only in blood (decreasing $\mathrm{HbA1}_{\mathrm{C}}$ levels) but also within the pancreas.

STZ induction is demonstrated to increase glycosylated hemoglobin, which is a marker with relation of surrounding glycemia during 2-3 month, implied the oxidation and damage in tissues. ${ }^{28,29}$ As expected, STZ induction resulted in a significant increase in blood $\mathrm{HbA1}_{\mathrm{C}}$ levels as compared with the CON mice, showing that oxidative damage exists following STZinduction. Administration of TRR reduced $\mathrm{HbA1}_{\mathrm{C}}$ levels, implying that TRR may provide a protective activity against oxidative damage caused by the glycation reaction in diabetic states.

STZ-induction is known to increase a production of ROS and reduced antioxidant enzyme such as superoxide dismutase (SOD), catalase, and glutathione peroxidase in the pancreas to be identified as the majority of the deterioration in the pancreas. ${ }^{30}$ Our pathological data showed that the STZ-induced diabetic islet displayed retraction from its classic round-shaped as compared with the control islet, which is consistent with a previous observation, ${ }^{31}$ implying that circulating ROS generated by STZ within the $\beta$-cell. Antioxidants have been suggested to afford protection to the pancreas against oxidative stress in diabetes mellitus. ${ }^{32}$ TRR belongs to one of triterpenoids, and many triterpenoids have shown with an antioxidant activity. ${ }^{33,34}$ In this study, we showed that administration of TRR increased the size of Langerhans islet cells and less distorted architecture within the pancreas, suggesting that TRR exerts an antioxidant activity within $\beta$-cells possibly by increasing radical scavenging 
and/or decreasing in ROS generation. TRR displayed a protective activity against the cytotoxicity and oxidant stress of STZ within the pancreas.

In this study, we showed that STZ-induction significantly increased fasting blood glucose levels, indicating that STZinduction displayed $\beta$ cell mass loss, and then insulin insufficiency, leading to hyperglycemia. A multiple low dose (MLD)STZ injections (35-55 mg kg ${ }^{-1}$ bodyweight for 4-5 consecutive days) are often used to model destruction of pancreatic $\beta$ cells, with a $70 \%$ reduction of the islet per pancreas area. ${ }^{35}$ Metformin and fenofibrate are oral drugs that are currently used to treat diabetes mellitus and hyperlipidemia, respectively. In this study, administration of TRR significantly reduced blood glucose levels, but increased plasma insulin levels compared with the STZ group. Moreover, we found that there is neither a decrease in blood glucose level nor an increase in plasma insulin levels by Metf and Feno treatment, suggesting that TRR, Feno, or Metf display different mode of actions in the regulation of blood glucose levels in STZ-induced diabetic mice. Metformin is reported to upregulate the synthesis of insulinotropic agents, such as glucagon like peptide-1 (GLP-1) through a mechanism requiring $\operatorname{PPAR} \alpha,{ }^{36}$ further support metformin is well suited for combination with incretin-based therapies. ${ }^{36}$ In this mode of MLD-STZ induced type 1 diabetic mice, Metf did not appear to lower blood glucose levels on the basis of a $70 \%$ decreased $\beta$-cell mass and insulin insufficiency, thus leading to ineffective in glycemic control. Although Metf is demonstrated to exhibit minor glucose-induced insulinotropic activities through stimulation of GLP-1; collectively, Meft is not an insulin secretagogue similar as fenofibrate. Taken together, the presented data imply that TRR may display blood glucoselowering effects via insulin secretagogue from the left $\beta$-cell and afterwards regeneration following STZ-destroy or/and antioxidant activities by $\mathrm{HbA} 1_{\mathrm{C}}$ levels and within the pancreas.

Streptozotocin-induced diabetes is known to display a severe loss in body weight, ${ }^{37}$ and this decrease in body weight is contributed to both the loss and degradation of structural proteins ${ }^{38}$ and the altered carbohydrate metabolism. ${ }^{38}$ Insulin is a key anabolic hormone. Because of decreased production of ATP and absolute or relative deficiency of insulin, protein synthesis is decreased in all tissues. ${ }^{39}$ In addition to blood glucose and $\mathrm{HbA}_{\mathrm{C}}$ levels, our results of decreasing body weights and lowering plasma insulin levels following STZinduction were in accordance with the previous study, ${ }^{37}$ and these further confirm that the model of STZ-induced diabetic mice was successfully set up. There was no difference on body weights between the TRR and the vehicle-treated STZ group. TRR caused a significant increase in insulin levels and a decrease in blood glucose levels. These results implied that TRR exerts an antidiabetic activity in STZ-induced Type 1 diabetic mice.

Two major cellular mechanisms have been suggested to account for promoted translocation of GLUT4 to the plasma membrane: insulin signaling through phosphatidylinositol $3^{\prime}$ kinase (PI3-kinase)/Akt pathway and the AMP-activated protein kinase (AMPK) pathway. ${ }^{40}$ It is clear that insulin signaling was an important mechanism for insulin-stimulating glucose uptake in skeletal muscles. ${ }^{\mathbf{4 1}}$ Skeletal muscular GLUT4 that is known to account for the majority of glucose uptake was included in this study as a means to evaluate antidiabetic mechanisms of TRR. In this study, expressions levels of membrane GLUT4 in skeletal muscles were suppressed in STZinduced diabetic mice as compared to the CON group, which is consistent with a previous study. ${ }^{42}$ We showed that TRR treatment not only increased phosphorylation of Akt in C2C12 myotubes but also in the animal study showing an increase in insulin levels and expression levels of p-Akt/t-Akt and p-AMPK/tAMPK in skeletal muscles, and a 3.04-5.42-fold increase in the expression levels of membrane GLUT4 as compared with the STZ group. The presented data implied that TRR treatment significantly promotes glucose transport across plasma membrane and markedly enhances the anti-diabetic effects in a mouse model of Type 1 DM, suggesting that TRR may exert its anti-diabetic effect through stimulating insulin-Akt or/and AMPK pathways.

Two major mechanisms have been suggested to account for decreased mRNA levels and expressions of PEPCK and G6 Pase gene transcription: insulin and phosphorylation of AMPK. ${ }^{\mathbf{4 3 , 4 4}}$ When the level of blood glucose is high, the pancreas releases insulin into the bloodstream. Insulin then causes the activation of PI3K, which subsequently phosphorylates Akt. Akt then phosphorylates FoxO1. ${ }^{45}$ This phosphorylated FoxO1 is irreversible; this prolongs insulin's inhibitory effect on glucose metabolism and hepatic glucose production. Transcription of G6 Pase subsequently decreases, which consequently decrease the rates of gluconeogenesis and glycogenolysis. ${ }^{46}$ Insulin inhibits gluconeogenesis via Akt-dependent phosphorylation of FoxO1, in turn, to inhibition of PEPCK and G6 Pase gene transcription. ${ }^{47}$ In this study, we showed that TRR increased blood insulin levels and enhanced hepatic expression levels of p-Akt and p-FoxO1, and this may result in a decrease in mRNA levels of G6 Pase and PEPCK, apparently leading to decreased hepatic glucose production. These results suggest TRR may act partly via insulin-Akt-FoxO1 and G6 Pase and PEPCK to inhibit hepatic glucose production and lower blood glucose levels.

In this study, STZ-induced diabetic mice displayed increased plasma TG and TC levels, consistent with a previous study. ${ }^{48}$ TRR treatment showed significantly lower level of blood TG $(32.4 \%-42.3 \%)$ and TC $(30.3 \%-38.9 \%)$ as compared to the STZ group. PPAR $\alpha$ agonists have been proposed as a breakthrough treatment to reduce blood triglyceride levels. ${ }^{49}$ Fenofibrate is one of the PPAR $\alpha$ agonists that may have blood triglyceridelowering effects and involve in fatty acid oxidation. ${ }^{50}$ Fatty acid synthase (FAS) is served as a key enzyme in fatty acid synthesis. ${ }^{51}$ In this study, we showed that STZ-induction caused an increase in expression levels of FAS but a decrease in PPAR $\alpha$ in the liver. Administration of TRR, Feno, and Metf significantly reduced expression levels of FAS, but enhanced the expression levels of PPAR $\alpha$, suggesting the involvement of mechanisms in TRR's anti-hyperlipidemic effects that TRR, Feno, and Metf appear to play an important role, possibly due to increases of $\beta$ oxidation but lack of FAS expression on prevention of hepatic triacylglycerol accumulation, in turn, inhibition of blood triglyceride levels. It was reported that PPAR $\alpha$-deficient mice 
displayed dysregulated SREBP-mediated lipogenic genes, ${ }^{52}$ further supporting the role of SREBP-1c in lipogenic transcription factor that contributes to fatty acid synthesis and TG accumulation. In this study, we showed that TRR suppressed mRNA levels of lipogenic SREBP1c to decreased hepatic triglyceride output, apparently leading to antihypertriglyceridemic effect of TRR. SREBP2 is known to play a key role in total cholesterol synthesis. ${ }^{53}$ In this study, plasma levels of TC were lowered following treatment with TRR may contribute to the decreased mRNA levels of SREBP2 to decrease the synthesis of TC. The overall results implied that TRR treatment display a reduction in expressions of FAS and mRNA levels of SREBP2, but an increase in PPAR $\alpha$ to exert an antihypertriglyceridemic and anti-hypercholesterolemic activity. Our data suggest that TRR may offer a possibility of efficacious treatment of type 1 diabetes accompanied with hypertriglyceridemia and/or hypercholesterolemia.

PPAR $\gamma$ is known to play an important role in stimulation of adipogenesis and lipogenesis. ${ }^{54}$ In this study, we showed that administration of TRR, Feno and Metf not only reduced expression levels of PPAR $\gamma$, with consequent reduced adipogenesis, but decreased lipid accumulation in liver tissues. Our data suggest that TRR may remove fat from adipose tissues to the liver through enhancing hepatic lipid catabolism and decreasing adipogenesis, thus leading to suppressing TG levels not only in the liver but also in plasma as well as almost absent in hepatic lipid droplets.

Administration of globular domains of adiponectin has been suggested to account for enhancing glucose uptake and fatty acid oxidation, and it is reported to be negatively associated with plasma lipid makers. ${ }^{55}$ Leptin is demonstrated to play a key role in the regulation of adipocyte differentiation and adipose tissue metabolism. ${ }^{56}$ In this study, we showed that administration of TRR increases plasma adiponectin levels, and TRR significantly enhanced leptin concentrations. Circulating lipids is known to move among blood, the liver, and adipose tissue. Thus, the beneficial effect of TRR was clearly associated with suppression of lipid synthesis and enhancement of fat oxidation and in relation to modulation of adiponectin and/or leptin secretion.

The researchers showed that leptin could substitute for insulin to control blood sugar fluctuations in patients with type 1 diabetes. ${ }^{57}$ Furthermore, the researchers showed that in a mouse model of type 1 diabetes, leptin was as effective as insulin in controlling blood sugar; nevertheless the mechanism of action is far from clear. These present data demonstrated that TRR had favorable effect on leptin levels, further suggesting that TRR plays a key role in glucose metabolism.

Recently, we have investigated and confirmed the antidiabetic and anti-hyperlipidemic effects of TRR in high-fatdiet (HFD)-induced type 2 diabetic mice. ${ }^{58}$ Type 2 diabetes mellitus have revealed mechanisms of insulin resistance that target the insulin insensitive action at adipose tissue, skeletal muscle, or liver tissues. Our previous data showed that the overall effect of TRR is to decrease glucose and triglyceride levels and improved peripheral insulin sensitivity. ${ }^{58}$ The model of C57BL/6J mouse that was fed a high fat-diet (HFD) is a robust and efficient model for early type 2 diabetes. ${ }^{59,60}$ The C57BL/6J mouse is susceptible not only to HFD-induced marked increases in adipose tissue mass but also to pronounced insulin resistance, hyperlipidemia, hyperinsulinemia, hypertriglyceridemia, and hypercholesterolemia. ${ }^{\mathbf{6 1}} \mathrm{HFD}$-induction for 14 weeks, mice increased both body weight and body weight gain. HFD-fed mice displayed an increase in relative weights of epididymal, retroperitoneal and mesenteric white adipose tissue, and visceral fat. ${ }^{58}$ TRR-treated mice significantly decreased the relative weights of epididymal WAT and visceral fat. ${ }^{58}$ Visceral adiposity is strongly linked to insulin resistance, type 2 diabetes, and dyslipidaemia. ${ }^{62}$ The HFD-fed mice displayed the significant hyperinsulinemia and hyperleptinemia, and TRR-treated mice significantly lowered levels of blood insulin and leptin, ${ }^{58}$ and these results are different from the present results showing STZ-induction display a decrease in blood insulin and leptin levels, and TRR treatment exhibited an increase in blood insulin and leptin levels. To our knowledge, insulin is the only clinic method to treat Type 1 DM. Our previous results concluded that TRR treatment not only significantly lowered the levels of blood glucose and insulin, triglycerides and total cholesterol, but also reduced visceral fat mass, and providing an outcome of TRR to have protective effects on insulin resistance in HFD-fed mice. ${ }^{58}$

STZ is widely used in inducing experimental animal models with type 1 DM. The STZ-induced diabetic rodent model is usually characterized by fasting or nonfasting hyperglycemia, and lowered serum insulin levels with hyperlipidemia; however, insulin resistance is often absent in this STZ-induced model.

In this study, STZ-induction decreased the size of adipocytes (different from the HFD-induced visceral obesity), and treatment with TRR increased the size of adipocyte but did not change the weights of epididymal WAT and visceral fat, and the reason may be due to few water retention or TRR's insulin-effect to promote adipose inflammatory ${ }^{63}$ and growth. Since STZinduced mice are too lean to collect adipose tissue, the expression levels of PPAR $\gamma$ were not examined to clarify whether TRR could enhance adipocyte differentiation or not. Further study still remains to be clarified.

The physiological phenomena of human are complex to keep glucose and lipid kinetic homeostasis among blood, skeletal, muscle, adipose, and liver tissue. Type 2 diabetes mellitus have revealed the majority of mechanisms of insulin resistance that target the insulin insensitive action at adipose tissue, skeletal muscle, or liver tissues. Based on structure activity relationship (SAR) and natural products from A. camphorata bearing similar structures of pentacyclic triterpenoid with strong antioxidant and excellent anti-diabetic activity (such as dehydroeburicoic acid: decreased blood glucose by $42 \%$ ), we investigated the antitype 2 diabetic and anti-hyperlipidemic activity using these tissues (skeletal, muscle, adipose, and liver tissue) to clarify how these compounds against insulin resistance. To clarify the effects of anti-type $1 \mathrm{DM}$, the pancreas are also included. Nevertheless, firstly, in vitro test, different model test was administered including assay of expressions of p-Akt's time course as compared with insulin in type $1 \mathrm{DM}$, or palmitateinduced insulin resistance. Regarding the anti-diabetic drugs, 


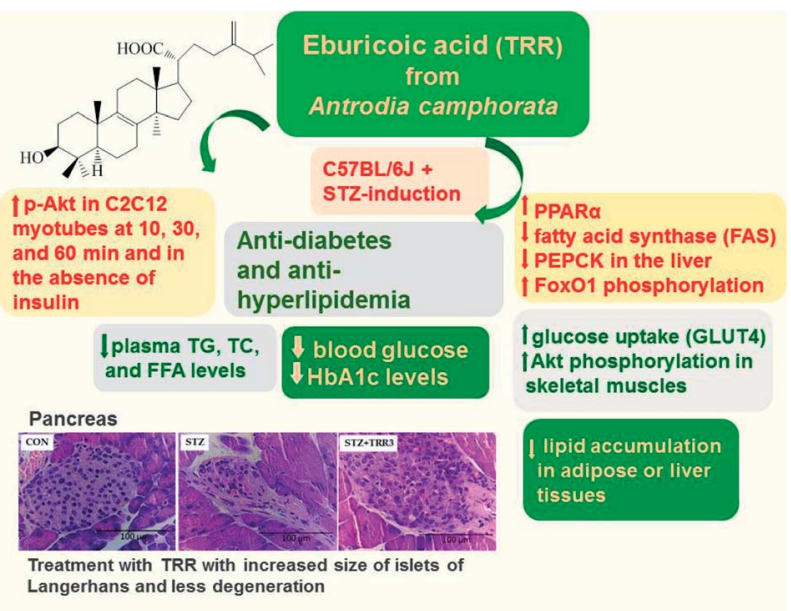

Fig. 7 The graphic abstract of eburicoic acid (TRR) in streptozotocininduced diabetic mice.

evidences have shown that canagliflozin is an inhibitor of sodium-glucose co-transporter 2 acting by inhibition of the reabsorption of glucose in proximal renal tubule. Acarbose is one of $\alpha$-glucosidase inhibitors in intestinal mucosa. Glucagonlike peptide-1 (GLP-1) and gastric inhibitory polypeptide (GIP) (releasing from gastrointestinal tract) is one of incretin hormones and could stimulate insulin secretion, and these applications including dipeptidyl peptidase-4 inhibitors (DPP IV inhibitors) have potential in the treatment of type 2 diabetes mellitus in the future. Whether TRR could modulate the kidney, intestinal mucosa, and gastrointestinal tract with anti-diabetic and anti-hyperlipidemic activity or not, further investigations remain to be conducted.

\section{Conclusions}

In summary (Fig. 7), TRR treatment was found to not only lower blood glucose and $\mathrm{HbA1}_{\mathrm{C}}$ levels, but also decrease plasma triglyceride and total cholesterol levels. Our findings showed that the STZ-induced diabetic islets are found to retraction from their classic round-shaped. Administration of TRR displayed improvement in the islets size and less degeneration. In vitro experiment, TRR was found to enhanced phosphorylation of Akt in the absence of insulin in C2C12 myotube, implying that TRR act as a regulator on insulin pathway (Akt). In the animal model, TRR enhanced the expressions of phosphorylation of Akt and activation of AMPK and membrane GLUT4 in skeletal muscles. Administration of TRR increased the blood insulin levels and enhanced hepatic expression levels of p-Akt and p-FoxO1 but decreased the mRNA levels of glucose-6-phosphatase (G6 Pase) to suppress hepatic glucose production. The overall TRR effect is to lead to antidiabetic activity of TRR. In the liver, TRR treatment increased the phosphorylation of AMPK and Akt, and enhanced the expression levels of PPAR $\alpha$, but reduced lipogenic FAS, thus leading to decreasing plasma triglyceride levels. TRR was found to exhibit the antioxidant activity in STZ-induced diabetic mice through mechanisms of decreases in $\mathrm{HbA1}_{\mathrm{C}}$ levels and improvements in histological examination within pancreas. Our results indicate that TRR may enhance optimal intervention strategies for type 1 diabetes and/or hyperlipidemia.

\section{Author contributions}

Chun-Ching Shih designed the whole experiment methods and had performed all data analysis of blood glucose levels, biochemical analysis, and western blot in vivo and in vitro, and wrote the manuscript. Cheng-Hsiu Lin had performed animal study and histological examination. Yueh-Hsiung Kuo had performed the NMR and HPLC analysis of TRR pure compounds and offered TRR pure compounds for the present study.

\section{Conflicts of interest}

The authors have declared that there are no conflicts of interest.

\section{Abbreviations}

$\begin{array}{ll}\text { BAT } & \text { Brown adipose tissue } \\ \text { CON } & \text { Control } \\ \text { EWAT } & \text { Epididymal white adipose tissue } \\ \text { Feno } & \text { Fenofibrate } \\ \text { FoxO1 } & \text { Forkhead transcription factor Foxo1 } \\ \text { GAPDH } & \text { Glyceraldehyde-3-phosphate dehydrogenase } \\ \text { G6 Pase } & \text { Glucose-6-phosphatase } \\ \text { GLUT4 } & \text { Glucose transporter } 4 \\ \text { Metf } & \text { Metformin } \\ \text { PEPCK } & \text { Phosphoenolpyruvate carboxykinase } \\ \text { PPAR } & \text { Peroxisome proliferator-activated receptor } \\ \text { RT-PCR } & \text { Reverse transcription-polymerase chain reaction } \\ \text { STZ } & \text { Streptozotocin } \\ \text { SREBP } & \text { Sterol regulatory element binding protein } \\ \text { TC } & \text { Total cholesterol } \\ \text { TG } & \text { Triglyceride } \\ \text { WAT } & \text { White adipose tissue }\end{array}$

\section{Acknowledgements}

Financial support for this study was provided by MOST1052320-B-166-001-(CC Shih's project) from Ministry of Science and Technology, Taiwan, and partly by China Medical University under the Taiwan Ministry of Health and Welfare Clinical Trial Center (MOHW107-TDU-B-212-123004).

\section{References}

1 D. Daneman, Type 1 diabetes, Lancet, 2006, 367(9513), 847858.

2 K. C. Tomlison, S. M. Cardiner and R. A. Hebden, Functional consequences of streptozotocin induced diabetes mellitus, with particular reference to the cardiovascular system, Pharmacol. Rev., 1992, 44, 103-150. 
3 K. Hayashi, R. Kojima and M. Ito, Strain differences in the diabetogenic activity of streptozotocin in mice, Biol. Pharm. Bull., 2006, 29(6), 1110-1119.

$4 \mathrm{H}$. Yin, J. Miao and Y. Zhang, Protective effect of $\beta$ casomorphin-7 on type 1 diabetes rats induced with streptozotocin, Peptides, 2010, 31, 1725-1729.

5 M. Elsner, B. Guldbakke, M. Tiedge, R. Munday and S. Lenzen, Relative importance of transport and alkylation for pancreatic beta-cell toxicity of streptozotocin, Diabetologia, 2004, 43(12), 1528-1533.

6 T. Szkudelski, The mechanism of alloxan and streptozotocin action in B cells of the rat pancreas, Physiol. Res., 2001, 50(6), 537-546.

7 R. A. Joshi, Antrodia camphorata with potential anticancerous activities: a review, J. Med. Plants Stud., 2017, 5(1), 284-291.

8 Y. W. Liu, K. H. Lu, C. T. Ho and L. Y. Sheen, Protective effects of Antrodia cinnamomea against liver injury, $J$. Tradit. Complement Med., 2012, 2(4), 284-294.

9 M. C. Kuo, C. Y. Chang, T. L. Cheng and M. J. Wu, Immunomodulatory effect of Antrodia camphorata mycelia and culture filtrate, J. Ethnopharmacol., 2008, 120(2), 196203.

10 T. Y. Song and G. C. Yen, Antioxidant properties of Antrodia camphorata in submerged culture, J. Agric. Food Chem., 2002, 50(11), 3322-3327.

11 Y. H. Kuo, C. H. Lin and C. C. Shih, Ergostatrien-3 $\beta$-ol from Antrodia camphorata inhibits diabetes and hyperlipidemia in high-fat-diet treated mice via regulation of hepatic related genes, glucose transporter 4, and AMP-Activated protein kinase phosphorylation, J. Agric. Food Chem., 2015a, 63(9), 2479-2489.

12 Y. H. Kuo, C. H. Lin and C. C. Shih, Antidiabetic and antihyperlipidemic properties of a triterpenoid compound, dehydroeburicoic acid, from Antrodia camphorata in vitro and in streptozotocin-induced mice, J. Agric. Food Chem., 2015b, 63(46), 10140-10151.

13 Y. H. Kuo, C. H. Lin and C. C. Shih, Dehydroeburicoic acid from Antrodia camphorata prevents the diabetic and dyslipidemic state via modulation of glucose transporter 4, peroxisome proliferator-activated receptor $\alpha$ expression and AMP-activated protein kinase phosphorylation in highfat-fed mice, Int. J. Mol. Sci., 2016, 17(6), 872, DOI: 10.3390/ ijms17060872.

14 A. A. Aiyegoro and A. I. Okoh, Preliminary phytochemical screening and in vitro antioxidant activities of the aqueous extract of Helichrysum longifolium DC, BMC Complementary Altern. Med., 2010, 10, 21.

15 A. Barthel and D. Schmoll, Novel concepts in insulin regulation of hepatic gluconeogenesis, Am. J. Physiol.: Endocrinol. Metab., 2003, 285(4), E685-E692.

16 G. J. Huang, J. S. Deng, S. S. Huang, C. Y. Lee, W. C. Hou, S. Y. Wang, P. J. Sung and P. J. Kuo, Hepatoprotective effects of eburicoic acid and dehydroeburicoic acid from Antrodia camphorata in a mouse model of acute hepatic injury, Food Chem., 2013, 141, 3020-3027.

17 C. C. Chen, Y. J. Shiao, R. D. Lin, Y. Y. Shao, M. N. Lai, C. C. Lin, et al., Neuroprotective diterpenes from the fruiting body of Antrodia camphorata, J. Nat. Prod., 2006, 69, 689-691.

18 E. Majid, K. B. Male, Y. M. Tzeng, J. O. Omamogho, J. D. Glennon and J. H. Luong, Cyclodextrin-modified capillary electrophoresis for achiral and chiral separation of ergostane and lanostane compounds extracted from the fruiting body of Antrodia camphorata, Electrophoresis, 2009, 30, 1967-1975.

19 C. H. Lin, J. B. Wu, J. Y. Jian and C. C. Shih, (-)-Epicatechin3-O- $\beta$-D-allopyranoside from Davallia formosana prevents diabetes and dyslipidemia in streptozotocin-induced diabetic mice, PLoS One, 2017, 12(3), e0173984, DOI: 10.1371/journal.pone.0173984.

20 C. C. Shih, M. H. Chen and C. H. Lin, Validation of the antidiabetic and hypolipidemic effects of Clitocybe nuda by assessment of glucose transporter 4 and gluconeogenesis and AMPK phosphorylation in streptozotocin-induced mice, J. Evidence-Based Complementary Altern. Med., 2014, 2014, 705636.

21 C. C. Shih, J. B. Wu, J. Y. Jian, C. H. Lin and C. H. Ho, (-)-Epicatechin-3-O- $\beta$-D-allopyranoside from Davallia formosana, prevents diabetes and hyperlipidemia by regulation of glucose transporter 4 and AMP-activated protein kinase phosphorylation in high-fat-fed mice, Int. J. Mol. Sci., 2015, 16(10), 24983-25001.

22 S. C. Stein, A. Woods, N. A. Jones, M. D. Davison and D. Carling, The regulation of AMP-activated protein kinase by phosphorylation, Biochem. J., 2000, 345(pt 3), 437-443.

23 C. C. Shih, C. H. Lin, W. L. Lin and J. B. Wu, Momordica charantia extract on insulin resistance and the skeletal muscle GLUT4 protein in fructose-fed rats, $J$. Ethnopharmacol., 2009, 123, 82-90.

24 A. Klip, T. Ramlal, D. A. Young and J. O. Holloszy, Insulininduced translocation of glucose transporters in rat hindlimb muscles, FEBS Lett., 1987, 224, 224-230.

25 A. Maritim, R. Sanders and J. Watkins, Effects of $\alpha$-lipoic acid on biomarkers of oxidative stress in streptozotocin-induced diabetic rats, J. Nutr. Biochem., 2003, 14, 288-294.

26 A. Vincent, J. Russell, P. Low and E. Feldman, Oxidative stress in the pathogenesis of diabetic neuropathy, Endocr. Rev., 2004, 25, 612-628.

27 D. E. Goldstein, R. R. Little, R. A. Lorenz, J. I. Malone, D. M. Nathan and C. M. Peterson, Tests of glycemia in diabetes, Diabetes Care, 2004, 27, S91-S93.

28 A. G. Huebschmann, J. G. Regensteiner, H. Vlassara and J. E. Reusch, Diabetes and advanced glycoxidation end products, Diabetes Care, 2006, 29, 1420-1432.

29 L. Al-Shamaorry, S. M. Al-Khazraji and H. A. Twaiji, Hypoglycemic effect of Artemisia herba alba II. Effect of a valuable extract on some blood glucose parameters in diabetic animals, J. Ethnopharmacol., 1994, 43, 167-171.

30 O. Coskun, M. Kanter, A. Korkmaz and S. Oter, Quercetin, a flavonoid antioxidant, prevents and protects streptozotocin-induced oxidative stress and beta-cell damage in rat pancreas, Pharmacol. Res., 2005, 51, 117-123.

31 H. Kaneto, Y. Kajimoto, J. Miyagawa, et al., Beneficial effects of antioxidants in diabetes: possible protection of pancreatic 
$\beta$-cells against glucose toxicity, Diabetes, 1999, 48, 23982406.

32 Z. Li, F. A. Karlsson and S. Sandler, Islet loss and alpha cell expansion in type 1 diabetes induced by multiple low-dose streptozotocin administration in mice, J. Endocrinol., 2000, 165, 93-99.

33 I. Gulcin, V. Mshvildadze, A. Gepdiremen and R. Elias, The antioxidant activity of a triterpenoid glycoside isolated from the berries of Hedera colchica: 3-O- $\left(\beta-\mathrm{D}^{-}\right.$ glucopyranosyl)-hederagenin, Phytother. Res., 2006, 20, 130-134.

34 C. Grace-Lynn, I. Darah, Y. Chen, L. Y. Latha, S. L. Jothy and S. Sasidharan, In vitro antioxidant activity potential of Lantadene A, a pentacyclic triterpenoids of Lantana plants, Molecules, 2012, 17, 1185-1198.

35 A. Maida, B. J. Lamont, X. Cao and D. J. Drucker, Metformin regulates the incretin receptor axis via a pathway dependent on peroxisome proliferator-activator- $\alpha$ in mice, Diabetologia, 2011, 5(2), 339-349.

36 J. S. Choi, T. Yokozawa and H. Oura, Improvement of hyperglycemia and hyperlipidemia in streptozotocindiabetic rats by a methanolic extract of Prunus davidiana stems and its main component, pruning, Planta Med., 1991, 57(3), 208-211.

37 L. Al-Shamaorry, S. M. Al-Khazraji and H. A. Twaiji, Hypoglycemic effect of Artemisia herba alba II. Effect of a valuable extract on some blood glucose parameters in diabetic animals, J. Ethnopharmacol., 1994, 43, 167-171.

38 L. Rajkumar, N. Srinivasan, K. Balasubramanian and P. Govindarajulu, Increased degradation of dermal collagen in diabetic rats, J. Exp. Biol., 1991, 29, 1081-1083.

39 R. R. Murray, D. K. Granner, O. A. Mayes and V. W. Rodwell, Harper's Biochemistry, Gluconeogenesis and the Control of Blood Glucose, Appleton and Lange, Stamford, Connecticut,2003, pp. 153-162.

40 G. I. Welsh, I. Hers, D. C. Berwick, et al., Role of protein kinase B in insulin-regulated glucose uptake, Biochem. Soc. Trans., 2005, 33(2), 346-349.

41 S. H. Liu, Y. H. Chang and M. T. Chiang, Chitosan reduces gluconeogenesis and increases glucose uptake in skeletal muscle in streptozotocin-induced diabetic rats, J. Agric. Food Chem., 2010, 58(9), 5795-5800.

42 P. A. Lochhead, I. P. Salt, K. S. Walker, D. G. Hardie and C. Sutherland, 5-Aminoimidazole-4-carboxamide riboside mimics the effects of insulin on the expression of the 2 key gluconeogenic genes PEPCK and glucose-6-phosphatase, Diabetes, 2005, 49, 896-903.

43 P. G. Quinn and D. Yeagley, Insulin regulation of PEPCK gene expression: a model for rapid and reversible modulation, Curr. Drug Targets: Immune, Endocr. Metab. Disord., 2005, 5(4), 423-437.

44 A. D. Cherrington, D. S. Edgerton and C. Ramnanan, The role of insulin in the regulation of PEPCK and gluconeogenesis in vivo, US Endocrinol., 2009, 5(1), 34-39.

45 H. Matsuzaki, H. Daitoku, M. Hatta, K. Tanaka and A. Fukamizu, Insulin-induced phosphorylation of FKHR
(Foxo1) targets to proteasomal degradation, Proc. Natl. Acad. Sci. U. S. A., 2003, 100(20), 11285-11290.

46 J. Nakae, T. Kitamura, D. L. Silver and D. Accili, The forkhead transcription factor Foxo1 (Fkhr) confers insulin sensitivity onto glucose-6-phospatase expression, J. Clin. Invest., 2001, 108(9), 1359-1367.

47 K. J. Oh, H. S. Han, M. J. Kim and S. H. Koo, CREBP and FoxO1: two transcription factors for the regulation of hepatic gluconeogenesis, BMB Rep., 2013, 46(12), 567-574.

$48 \mathrm{~J}$. S. Choi, T. Yokozawa and H. Oura, Improvement of hyperglycemia and hyperlipidemia in streptozotocindiabetic rats by a methanolic extract of Prunus davidiana stems and its main component, pruning, Planta Med., 1991, 57(3), 208-211.

49 A. Barthel and D. Schmoll, Novel concepts in insulin regulation of hepatic gluconeogenesis, Am. J. Physiol.: Endocrinol. Metab., 2003, 285(4), E685-E692.

50 S. C. Hsu and C. J. Huang, Reduced fat mass in rats fed a high oleic acid-rich safflower oil diet is associated with changes in expression of hepatic PPARalpha and adipose SREBP-1c-regulated genes, J. Nutr., 2016, 136(7), 1779-1785.

51 S. Wakil, Fatty acid synthase, a proficient multifunctional enzyme, Biochemistry, 1989, 28(11), 4523-4530.

52 H. Shimano, N. Yahagi, M. Amemiya-Kudo, et al., Sterol regulatory element-binding protein-1 as a key transcription factor for nutritional induction of lipogenic enzyme genes, J. Biol. Chem., 1999, 274(50), 35832-35839.

53 J. D. Horton, I. Shimomura, M. S. Brown, R. E. Hammer, J. L. Goldstein and H. Shimano, Activation of cholesterol synthesis in preference to fatty acid synthesis in liver and adipose tissue of transgenic mice overproducing sterol regulatory element-binding protein-2, J. Clin. Invest., 1998, 101(11), 2331-2339.

54 R. Saladin, L. Fajas, S. Dana, Y.-D. Halvorsen, J. Auwerx and M. Briggs, Differential regulation of peroxisome proliferator activated receptor gamma1 (PPARgamma1) and PPARgamma2 messenger RNA expression in the early stages of adipogenesis, Cell Growth Differ., 1999, 10, 43-48.

55 X. Wu, H. Motoshima, K. Mahadev, T. J. Stalker, R. Scalia and B. J. Goldstein, Involvement of AMP-activated protein kinase in glucose uptake stimulated by the globular domain of adiponectin in primary rat adipocytes, Diabetes, 2003, 52(6), 1355-1363.

56 J. P. Bastard, B. Hainque, E. Dusserre, E. Bruckert, D. Robin, P. Vallier, et al., Peroxisome proliferator-activated receptorgamma, leptin and tumor necrosis factor-alpha RNA expression during very low calorie diet in subcutaneous adipose tissue in obese women, Diabetes/Metab. Res. Rev., 1999, 15(2), 92-98.

57 M. Y. Wang, L. Chen, G. O. Clark, Y. Lee, R. D. Stevens, O. R. Ilkayeva, et al., Leptin therapy in insulin-deficient type 1 diabetes, Proc. Natl. Acad. Sci. U. S. A., 2010, 107(11), 4813-4819.

58 C. H. Lin, Y. H. Kuo and C. C. Shih, Eburicoic acid, a triterpenoid compound from Antrodia camphorata, displays antidiabetic and antihyperlipidemic effects in palmitate-treated C2C12 myotubes and in high-fat diet-fed 
Mice, Int. J. Mol. Sci., 2017, 18, 2314, DOI: 10.3390/ ijms18112314.

59 M. Kobayashi, T. Ohno, T. Tsuchiya and F. Horio, Characterization of diabetes traits in MSM and JF1 mice on high fat diet, J. Nutr. Biochem., 2004, 15, 614-621.

60 A. E. Petro, J. Cotter, D. A. Cooper, J. C. Peters, S. J. Surwit and R. S. Surwit, Fat, carbohydrate and calories in the development of diabetes and obesity in the C57BL/6J mouse, Metabolism, 2004, 53, 454-457.

61 R. A. K. Srivastava, R. Jahagirdar, S. Azhar, S. Sharma and C. L. Bisgaier, Peroxisome proliferator-activated receptor- $\alpha$ - selective ligand reduces adiposity, improves insulin sensitivity, and inhibits atherosclerosis in LDL receptordeficient mice, Mol. Cell. Biochem., 2006, 285(1-2), 35-50.

62 D. J. Evans, R. G. Hoffmann, R. K. Kalkhoff and A. H. Kissebah, Relationship of body fat topography to insulin sensitivity and metabolic profiles in premenopausal women, Metabolism, 1984, 33, 68-75.

63 D. J. Pedersen, A. Guilherme, L. V. Danai, L. Heyda, A. Matevossian, J. Cohen, et al., A major role of insulin in promoting obesity-associated adipose tissue inflammation, Mol. Metab., 2015, 4(7), 507-518. 